\title{
Para uma leitura (modernista) de Max Stirner
}

\author{
On a (modernist) reading of Max Stirner
}

\author{
Rodrigo Ornelas \\ ornelas.rodrigo@hotmail.com \\ (Universidade Federal da Bahia, Bahia, Brasil)
}

\begin{abstract}
Resumo: Destinado aos interessados no movimento jovem hegeliano e, em especial, no pensamento de Max Stirner, este texto sugere certo roteiro para leitura do autor, passando do panorama histórico-filosófico à apresentação crítica de três pontos de partida para Stirner, como: 1) anarquista, por Engels e teóricos do anarquismo; 2) idealista, por Marx/Engels na Ideologia Alemã, reforçado por autores influenciados doutrinariamente por ambos; e 3) modernista, por filósofos comentadores contemporâneos de Stirner (como Camus, Stepelevich, Penzo e, principalmente, José Crisóstomo de Souza). Defenderei, no entanto, o último, passando da exposição histórica de Stirner na filosofia pós-hegeliana à crítica das outras linhas interpretativas.
\end{abstract}

Palavras-chave: modernidade; hegelianismo; anarquismo; idealismo; egoísmo.
Abstract: Intended for those interested in the young Hegelians, and especially in Max Stirner's thought, this text suggests a certain script for reading the author, going from a historical-philosophical panorama to the critical presentation of three starting points for Stirner, as: 1) an Anarchist, by Engels and anarchism theorists; 2) an Idealist, by Marx/ Engels, reinforced by authors influenced doctrinally by both; and 3) a Modernist, by contemporary philosophers and Stirner's commentators (such as Camus, Stepelevich, Penzo and especially Souza). However, I'll defend the last one, since a Stirner's historical exposition in post-Hegelian philosophy to the critique of other interpretive lines.

Keywords: modernity; hegelianism; anarchism; idealism; egoism.

DOI: http://dx.doi.org/10.11606/issn.2318-9800.v23i1p27-40

\section{Stirner no movimento jovem hegeliano}

Como aponta Lawrence Stepelevich, “o pensamento original de Hegel” era "explicitamente centrado sobre a restauração da metafísica, teologia especulativa e da teoria social e política conservadora" (Stepelevich, 1999, p.2). Seus alunos e seguidores, então, dividiram-se entre aqueles que levaram esse pensamento adiante ortodoxamente e aqueles que, partindo do próprio sistema hegeliano, se opuseram ao filósofo, numa postura “dialética antitética” (Wartofsky \& Saß, 1978, p.3). Quando Max Stirner escreveu O Único e a sua Propriedade, em 1844 (publicado em 1845), estava chegando a uma das consequências dessa crítica, num dos limites do movimento conhecido como Jovem Hegeliano. Mas para situarmos as concepções filosóficas da 
obra de Stirner, voltaremos às duas grandes obras que podemos considerar como marcos iniciais do movimento: A Vida de Jesus, examinada criticamente (1835), de David Strauss, e A Essência do Cristianismo (1841), de Ludwig Feuerbach.

Tomando esses dois textos como pontos de partida, e usando uma classificação baueriana - posteriormente também usada por Marx (cf. respectivamente, Bauer, 1989, e Marx \& Engels, 2007) -, podemos dizer que o primeiro desdobramento de Hegel na esquerda hegeliana se deu pelo viés da substância. Strauss desenvolve uma crítica da religião deslocando a encarnação de Deus do indivíduo Jesus Cristo para a humanidade (cf. Souza, 1992, p.14; e Stepelevich, 1999, p.19). Feuerbach, por sua vez, demonstra que Deus é a essência objetiva do Homem, e que a teologia é uma antropologia (Feuerbach, 2009, p.67), fazendo uma distinção aqui também entre o indivíduo (particular) e a espécie - o Ser-genérico, Gattungswesen.

Logo que publicadas, ambas as obras foram seguidas por dois textos de outro jovem hegeliano, que justamente mudou a direção do movimento para o aspecto antisubstancialista, para a concepção hegeliana de autoconsciência (Selbstbewußtsein): o teólogo e filósofo Bruno Bauer. Primeiro, ainda apresentando-se como um hegeliano de direita, próximo a Philip Marheineke, Bauer escreve uma resposta ao livro de Strauss. Depois, já imerso nas ideias hegelianas "revolucionárias" (na chamada esquerda hegeliana), Bauer publicará um panfleto intitulado $A$ Trombeta do Juízo Final Contra Hegel Ateu e Anticristo: um ultimado (1841), onde diferenciará dois caminhos para a leitura de Hegel: o da substância e o da autoconsciência. É o segundo caminho que Bauer tomará para erigir sua crítica radical da religião, que todo jovem hegeliano pretendia. E dentre os jovens alunos de Hegel que se inclinaram mais às posições de Bauer está Max Stirner, que escreve um artigo elogioso sobre a Trombeta. A partir daí Stirner passa a frequentar o grupo que se reunia em torno de Bauer - os Livres (Die Freien), o núcleo mais radical da esquerda hegeliana (Souza, 1992, p.21) - onde irá amadurecer suas ideias, primeiramente mais próximas do amigo, até criar um novo rompimento (e mais radical) com a filosofia, não só de Hegel, Feuerbach, Moses Heß, Proudhon, como também do próprio Bruno Bauer.

Dentro da dialética hegeliana Stirner constrói sua caracterização da modernidade em sua história do desenvolvimento de "uma vida humana"1, quando compara a época coroada por Hegel com a juventude, o fim da infância - ou o fim do primeiro estágio do pensamento e da história ocidental - como um momento de confronto, e, logo depois, a condescendência, com os "pensamentos abstratos", ou seja, as ideias (Stepelevich, 2005, p.168). Stirner (como Hegel) considera que o "jovem" possui o sentimento revolucionário, inspirado por ideais. Stepelevich, sobre isso, desenvolve:

1 Primeiro capítulo de 0 Único e a sua Propriedade. 
Estes sentimentos da juventude como sentimento-de-si, que coloca os jovens num "ponto de vista celestial", constitui uma base importante da crítica de Stirner ao projeto de Feuerbach como um projeto adolescente, entendido como tal apenas por alguém que tinha ele próprio transcendido à adolescência - em resumo, ein Mann (um homem). Stirner considera-se não apenas um Mann (homem), mas também um homem singular, um Einziger (único) (idem, p. 171).

"Ao projeto de Feuerbach" e, podemos acrescentar, de modo geral, a todo movimento hegeliano. Stirner reage a Hegel quando critica o "império dos grandes sistemas”, o “mundo das grandes abstrações” (Díaz, 2002, p.23). Ele rejeita as “ideias fixas", que acompanham a filosofia desde os primórdios. Para Franco Volpi, como “[p] ríncipe dos iconoclastas modernos, Stirner pretende pôr abaixo todos os sistemas filosóficos, toda e qualquer abstração ou ideia" (Volpi, 1999, p.33). Hegel e os hegelianos de direita, como monarquistas protestantes e conservadores, associaram a Ideia ao Estado e à religião. Feuerbach e Strauss (e Moses Heß, por exemplo, na sociedade) haviam deslocado nossa essência, também um ideal, de uma entidade religiosa para uma entidade humana. Stirner entende que isso não muda o fato de a ideia ainda existir (transcendente e sacralizadamente) e, portanto, esses primeiros jovens hegelianos ainda permaneciam “adolescentes”, ideológicos - ou "possuídos, como colocará n’O Único (Stirner, 2009, pp47-52).

É expressamente a des-substancialização da filosofia inaugurada por Bruno Bauer que fará Stirner se aproximar deste filósofo. Inicialmente através da já referida resenha sobre a Trombeta, tomando-a como uma crítica "livre e inteligente" (Über B. Bauer Posaune des jüngsten Gerichts in Stirner, 2011, p.25), um "ataque radical sobre Hegel”, num livro de "deliciosa mistificação" (idem, pp.13-14); ${ }^{2}$ e depois na aproximação direta com Os Livres. As ideias de Stirner podem ser localizadas como sucessoras da filosofia de Bauer, desenvolvendo, do indivíduo universalizado baueriano - decorrente da sua filosofia pós-hegeliana da autoconsciência e da liberdade - o seu indivíduo particular (o único).

Mas do mesmo modo que o radicalismo de Bauer aqueceu o debate jovem hegeliano, a divergência de Stirner para uma corrente própria e ainda mais radical movimentou todo o cenário em que ele se encontrava. O Único e sua Propriedade recebeu, ainda em 1845, três críticas - de Szeliga, Feuerbach e Moses Heß - às quais Stirner respondeu no artigo Os Críticos de Stirner, do mesmo ano. No ano seguinte foi criticado por Karl Schmidt, em O Reino do Intelecto e o Indivíduo. Mais tarde foi criticado por Kuno Fischer, num texto de 1847, chamado Os Sofistas Modernos, este também respondido por Stirner no mesmo ano, no artigo Os Filósofos Reacionários, assinando como G. Edward. A principal tese defendida por seus críticos

2 É importante lembrar que neste seu panfleto, Bauer escreve anonimamente como um cristão que denuncia em Hegel um lado ateísta, que chega, inclusive, a "matar Deus" - inaugurando certo radicalismo na crítica da religião entre os jovens hegelianos. 
é que seu único, ou o seu egoísta, são também ideias absolutizadas e, como as ideias criticadas por Stirner, também sacralizadas. Feuerbach, por exemplo, em A Essência do Cristianismo em relação com O Único e a sua Propriedade (1845), vai questionar: ${ }^{3}$

O Único afirma que tem sua causa em nada depositada. Mas não é este "nada" um predicado de Deus, e não é a sentença "Deus é nada", uma expressão da consciência religiosa? Então, o Egoísta tem ainda, apesar de tudo, baseado seus sentimentos em Deus! Então ele ainda pertence aos "ateístas devotos" (Feuerbach, 1978, p.81). ${ }^{4}$

A resposta poderia ser encontrada no próprio $O$ Único, escrito em primeira pessoa e em linguagem inteiramente contingencial. Mas Stirner responde diretamente no outro texto (referindo-se a ele mesmo agora na terceira pessoa):

Stirner fala do Único e diz imediatamente: Nomes, o nome não é você. Ele articula a palavra, logo quando ele chama isto de Único, acrescenta, não obstante, que o Único é apenas um nome. Ele, portanto, tem em mente alguma coisa diferente do que ele diz, como talvez alguém que chama você de Ludwig mas não tem em mente um Ludwig em geral e sim você, para o que ele não tem palavras (Stirner, 1978, p.67).

E continua, em resposta aos textos de Szeliga (uma crítica publicada na Norddetschen Blätter), Feuerbach (A Essência do Cristianismo em relação com 0 Único e a sua Propriedade) e Moses Heß (Os Últimos Filósofos):

Szeliga se dá ao trabalho de mostrar que o “Único", medido pelo seu próprio princípio de ver fantasmas em todo lugar, torna-se o fantasma de todos os fantasmas. Escapathe que o Único é uma frase vazia. Que ele próprio, Szeliga, é o teor dessa frase, ele permite que isso escape de sua atenção. (...) Stirner aventura-se a dizer que Feuerbach, Heß e Szeliga são egoístas. Com isso, Stirner, claro, faz o julgamento idêntico como quando ele diz que Feuerbach não faz absolutamente nada mais que o que é Feuerbachiano, que Heß não faz nada mais que o que é Hessiano, e Szeliga não faz nada exceto o que é Szeliganiano. No entanto, apenas Stirner lhes deu um título completamente notório (idem, pp.70-71).

O impacto do livro de Max Stirner pode ser medido na mudança de direção do movimento jovem hegeliano - e quiçá no seu fim (como, por exemplo, sugere José Crisóstomo de Souza - 1992, p.56). Bruno Bauer demonstra-se tocado pelas posições críticas de Stirner num texto de 1845, intitulado Caracterização de Feuerbach, de tal modo que Marx e Engels chegam a dizer que Bauer copia "desastradamente" Stirner para criticar Feuerbach (2007, p.102) - ainda que no mesmo texto Bauer também faça uma crítica a Stirner parecida com a de Feuerbach, sugerindo que o único stirneriano, o egoísta, seria apenas o oposto, a negação abstrata, o outro lado, do homem genérico de Feuerbach, “o comunitário”, “o sagrado”, etc. (Souza, 1992, p.96). Feuerbach, mais tarde, também apresenta mudanças na relação entre

3 Referindo-se à frase que abre $O$ Único: "Tenho minha causa sobre Nada depositada".

4 Uma resposta ao trecho em que Stirner, referindo-se (também) a Feuerbach, diz que "Nossos ateus são pessoas devotas" (Stirner, 2009, p.239). 
espécie e indivíduo, apresentando agora uma noção de Gênero menos "inflada e intrinsecamente ligado ao indivíduo". 5 mesmo ocorre com Marx e Engels que, em 1844, criticavam Bruno Bauer e seus consortes de modo clara e assumidamente feuerbachiano, mas em 1845 (ano que caracteriza o conhecido "corte epistemológico" de Marx), após a publicação d'O Único, rompem com Feuerbach, numa crítica justamente à concepção de essência-genérica deste último, como "generalidade interna, muda, que une muitos indivíduos de modo natural” (Marx \& Engels, 2007, p.534). Stepelevich descreve esse quadro pós-Único: “depois do trabalho de Stirner, Feuerbach praticamente deixou de publicar, e Marx renunciou a seu papel como discípulo de Feuerbach com a sua breve, e crítica, Teses ad Feuerbach" (Stepelevich, 2005, p.172). Em publicações dos anos de 1860, Feuerbach, na verdade, admite que "pouco restava do conceito-chave de A Essência do Cristianismo, que foi o principal alvo da crítica de Stirner. (...) Feuerbach apresenta uma teoria do conhecimento que foi baseada na intuição sensível imediata de particulares” (Gordon, 1978, p.53).

Esse é o quadro histórico-ideológico em que se localiza o pensamento de Stirner. Os desdobramentos de uma tendência propriamente stirneriana só aparecerão no fim do século XIX, muito depois da morte do filósofo, a partir da recuperação de sua obra feita pelo poeta anarquista John Henry Mackay. Mas estas tendências, ou simplesmente sua influência, serão mais bem entendidas numa análise das direções dadas ao seu pensamento, na filosofia e na teoria política.

\section{Um ponto de partida para Stirner}

De modo geral, podemos propor três grandes linhas de leitura para a obra de Max Stirner: do filósofo como (1) anarquista, (2) idealista, ou (3) modernista. Tratemos agora de expor criticamente os principais argumentos usados para localizar o autor nessas três posições, de maneira que possamos embasar um alinhamento com a terceira opção (ainda que eu, pessoalmente, considere e, em alguns aspectos, absorva as outras duas). Este modo de entender Stirner o coloca como um crítico da Modernidade, mas de dentro da Modernidade e realizando-a em última instância; como ruptura e autocrítica radical, para levá-la à sua realização máxima - o que aqui chamo de posição modernista.

\footnotetext{
5 "Tendes total razão, meus senhores, pensei eu contra meus críticos; sei tão bem quanto vós, talvez até melhor, que um ser humano pensado como um ser absoluto, somente por si é um contrassenso, uma quimera ideal"; e mais à frente, "O sujeito, isto é, o Ser existente, é sempre o Indivíduo, a espécie é apenas o predicado (...) o Gênero só existe enquanto Indivíduo ou predicado do Indivíduo" (Feuerbach, 2009, p.32-33; pp.141-144).
} 
Passemos, então, aos três tópicos de possíveis pontos de partida para Stirner.

\section{O anarco-individualista radical}

A ideia de Stirner ser uma espécie de anarquista, na realidade, começa com Friedrich Engels, que, por mais de uma vez, o caracteriza como influenciador direto de Bakunin e dos anarquistas da segunda metade do século XIX. Na primeira parte de Ludwig Feuerbach e o Fim da Filosofia Clássica Alemã, de 1886, Engels irá traçar um panorama do que foi a herança de Hegel para os jovens hegelianos. Nessa apresentação, o autor aponta a contribuição de Stirner ao movimento, respondendo à sua própria questão sobre até onde foi a polêmica em torno da substância e da consciência. Engels diz: “finalmente, apareceu Stirner, o profeta do anarquismo moderno - pois o próprio Bakunin muito lhe deve - e coroou a 'consciência' soberana com a ajuda do seu sujeito 'único' e soberano” (Engels, s/d, p.177). Mais tarde, o autor volta a repetir a aproximação de Stirner com Bakunin e os anarquistas modernos, em uma carta a Max Hildebrand, de 1889:

Stirner viveu um renascimento através de Bakunin, que, aliás, naquela época, também estava em Berlin, e no curso sobre lógica de Werders sentava no banco da minha frente, com ainda 4 ou 5 russos (1841/42). A anarquia ingênua, apenas etimológica (quer dizer, ausência de um poder do Estado) de Proudhon, nunca tinha sido levada às atuais correntes anarquistas; Bakunin ainda não tinha vertido nela uma boa parte da "revolta" [Empörung] stirneriana (Marx \& Engels, 1956).

De fato, é sustentando esta proposta que alguns dos principais teóricos do anarquismo e anarquistas contemporâneos, como Émile Armand, George Woodcock e Daniel Guérin, situam Stirner como um anarco-individualista. E como o principal, na verdade. Um sucessor de William Godwin e Proudhon, predecessor de Bakunin e Anselme Bellegarrigue, por exemplo (cf., p. ex., Woodcock, 2010). Para Günther Freitag, ele é o próprio "fundador e teórico do anarquismo individualista" (Armand, Barrué \& Freitag, 2003, p.11).

Esta leitura se deve principalmente a dois aspectos da obra de Stirner: (1) a dissolução do Estado e da sociedade, associada à sua crítica das hierarquias, e (2) a proposta de organizações por associações (Verein). Ao criticar qualquer força superior a ele mesmo, qualquer ideia ou instituição que se apresente como um senhor ao único, Stirner realmente faz jus ao princípio mais básico do anarquismo, qual seja, a abolição do governo (Woodcock, 2010, p.8), do mesmo modo que quando propõe uma associação de indivíduos radicalmente livres (idem, pp.11-12); e principalmente quando o autor associa a isto uma crítica do socialismo como uma nova hierarquia e propõe a revolta (Empörung) no lugar da revolução - que apenas substituiria instituições antigas por novas, conferindo-lhes o mesmo "caráter sagrado" que 
tinham as anteriores (Armand et al, 2003, p.68).

$\mathrm{O}$ anarquismo stirneriano pode ser resumido na seguinte definição de Woodcock:

Como qualquer outro típico filósofo anarquista, Stirner critica a sociedade vigente por seu caráter autoritário e anti-individualista e propõe uma situação desejável, que, entretanto, só poderia ser atingida após a derrubada das instituições governamentais. Ele exige que haja igualdade entre todos os egoístas, mesmo que a veja em termos de tensão criada pelo equilíbrio de forças; e sugere - embora de forma um tanto vaga - meios insurrecionais através dos quais seria possível transformar a sociedade (Woodcock, 2010, p.103).

Entretanto, podemos fazer três objeções a essa leitura e que servem para a leitura de Stirner simplesmente como anarquista. Primeiro, ainda que realmente se oponha ao governo, Stirner não pretende "derrubar as instituições governamentais”. $\mathrm{O}$ autor apenas retira todo poder exterior ao único imediatamente quando deixa de reconhecê-lo, quando entende que ele, e apenas ele, é senhor de tudo, uma vez que tanto o governo quanto as suas instituições são meras ideias, abstrações, criações dele e, portanto, propriedade dele (um sujeito corpóreo, real, por assim dizer) - e não o contrário. Segundo, Stirner não exige nada para todos (muito menos uma igualdade), mas, no máximo, apenas para ele (que quando fala, é o único). Tanto porque sua relação com outro é egoísta e de conflito, quanto porque ele não tem de quem exigir, uma vez que não reconhece nada acima de si mesmo. E, por fim, Stirner, declaradamente, não só não sugere uma transformação da sociedade, como critica tal coisa. Tomar Stirner como mero anarquista pode nos levar a cair na armadilha do mesmo círculo vicioso que o autor aponta em seus contemporâneos, bem como seus contemporâneos tentaram apontar nele, o tal círculo mágico do cristianismo: o de uma concepção que ainda carrega a marca do sagrado. O próprio Woodcock conta que chegou a encontrar, em 1940, “um grupo de operários anarquistas em Glascow que julgavam o livro [O Único] uma espécie de evangelho” (Woodcock, 2010, p.107). O anarquista contemporâneo Murray Bookchin, numa autocrítica do movimento, adjetiva o único de Stirner por "metafísico", e afirma que, “longe disso, os militantes anarquistas precisavam de uma literatura básica, que fosse pragmática, discursiva e teórica” (Bookchin, 2010, p.52).

A despeito desta caracterização, J. Crisóstomo de Souza aponta:

É verdade que quem tem dado maior atenção a Stirner, ao menos até alguns anos atrás, têm sido principalmente os autores anarquistas. Na qualidade de defensor da individualidade e crítico do Estado, Stirner pode bem fazer o papel de pioneiro do anarquismo individualista; mas seria um erro tomá-lo por defensor de algum ideário político ou social (Souza, 1993, p.177).

Este foi o principal modo de leitura de Stirner até hoje, ${ }^{6}$ tanto positiva, quanto

6 A maioria das traduções de Stirner, por exemplo, foram feitas por anarquistas, ou por comentadores que vão caracterizá-lo como anarquista. 
negativamente. Mas não foi nem o primeiro, nem o menos exagerado. Logo que da publicação d'O Único, Max Stirner foi também lido como um idealista, em meio a outros hegelianos, num texto mais aprofundado e atento que outras críticas da época: São Max, que integra A Ideologia Alemã, e que só se tornou público em 1903, de modo que, cronologicamente, será o nosso segundo tópico.

\section{Sankt Max como um "idealista historicista"}

O segundo ponto de partida para uma leitura de Stirner deve-se, principalmente, à crítica de Marx/Engels (e marxistas) ao filósofo do egoísmo. Na série de trabalhos que compõem A Ideologia Alemã, correspondendo à maior parte de sua extensão, está o texto Sankt Max ("São Max"), escrito em 1845, mas que não foi publicado imediatamente, sendo conhecido apenas 20 anos após a morte de Marx. Uma crítica irônica e minuciosa de $O$ Único e sua Propriedade, que o próprio Engels irá descrever como "tão espessa quanto o próprio livro" (em carta a Max Hildebrand, de 22 de outubro de 1889 - Marx \& Engels, 1956) - é, na verdade, a obra mais extensa que Marx escreveu para publicação, depois de O Capital (Souza, 1993, p.179). Nesse calhamaço crítico, os autores apontam Stirner como um dos representantes do idealismo alemão - ainda que provavelmente tenha sido, segundo Rudolf Hirsch, "o adversário mais poderoso" que Marx jamais enfrentou (apud idem, 177), haja vista o trabalho que tiveram Marx e Engels para redigir Sankt Max.

No prefácio de Para a Crítica da Economia Política, Marx irá indicar A Ideologia Alemã (ainda chamada de "o manuscrito") como a elaboração de uma "oposição contra o que há de ideológico na filosofia alemã” (Marx, 2005, p.53). Em A Ideologia Alemã, Marx e Engels dirão (se referindo a Stirner por Jacques ${ }^{7}$ ):

O profundo Jacques se dá ares de que nada haveria a dizer desse único, por ser ele um indivíduo corpóreo, não passível de construção. Mas o que ocorre aqui é, antes, o mesmo que se dá com a ideia absoluta de Hegel no final da Lógica e com a personalidade absoluta no fim da Enciclopédia, das quais tampouco há o que dizer porque sua construção já contém tudo o que pode ser dito de tais personalidade construídas (Marx \& Engels, 2007, p.236).

Para os pais do socialismo científico, o idealismo de Stirner seria o limite do idealismo hegeliano que os seus jovens seguidores desenvolveram (Feuerbach, Bruno Bauer, etc., também contemplados n'A Ideologia). E assim também Paulo Arantes entende a posição do autor d'O Único:

A considerável irrealidade das "ideias modernas" no cenário alemão dá lugar a uma realidade redobrada no plano do ideal. A lógica deste movimento encontrará sua expressão acabada em Stirner, em cuja crítica tomará corpo o contrassenso do

7 De Jacques, le bonhomme, como depreciativamente os nobres franceses chamavam os camponeses. 
liberalismo alemão, variando-o noutra direção. Antes de prosseguir conviria referir um ponto de ordem geral: a rigor, o Idealismo alemão e o seu epílogo jovem-hegeliano não se distinguem das demais ideologias (...) quando consideram a sociedade e a sua história “dominadas" pelas ideias (Arantes, 1996, p.367).

Entretanto, numa leitura mais apurada da obra de Marx, podemos entender que sua crítica a Stirner não é tão simples quando parece, diante do modo ridicularizado com que os autores descrevem $O$ Único e seu autor. Podemos ver que há mais que uma mera generalização de Stirner como "mais um” idealista - primeiro, pelo tamanho do texto, uma vez que a Bauer, Feuerbach e alguns socialistas alemães, os outros criticados n'A Ideologia, são dedicadas menos da metade do texto completo e, segundo, pelo estilo “difícil e pouco agradável” (Henri Arvon apud Souza, 1993, p.186). ${ }^{8}$ A questão é que Stirner já trazia n’o Único uma oposição bem fundada acerca do sujeito e da individualidade que Marx procurava formular. Este último, um ponto de vista mais substancialista e essencialista que o de Feuerbach. De acordo com J. Crisóstomo de Souza:

Na Ideologia Alemã, (...) Marx está disposto a defender que a verdadeira essência existe realmente "fora de nossas cabeças", e que a "substância em processo" é uma realidade palpável, material. (...) Para Marx, definitivamente, "homem" ou "fruta", sua essência não está no indivíduo, que é algo "posto" (como mal ou bem intui a “especulação”) por uma “substância material objetiva” (Souza, 1992, p.109).

Marx entende que "o empenho de Stirner para que os homens, como 'únicos', livrem-se de toda generalidade imposta" reduz a substância a "simples acidente" (Souza, 1992, p.111), enquanto Stirner quer mesmo se livrar de ideias como "substância” ou "essência”.

Da polêmica entre Marx e Stirner, e da caracterização deste último como um idealista, podemos então concluir, novamente nas palavras de J. Crisóstomo de Souza:

A ideia tão generalizada de que Stirner é um idealista ingênuo que simplesmente quer mudar o mundo pela critica das ideias e ilusões está entre uma distorção absurda e uma simplificação exagerada. A preocupação em transformar o mundo - na verdade, abraçada por Marx - representa para Stirner uma aspiração tipicamente juvenil, idealista, e mesmo “religiosa” (Souza, 1993, pp.185-186)

Para Souza, “na Ideologia Alemã, mais exatamente no 'São Max', Marx desenvolve seu ponto de vista sobre a individualidade. E a 'individualidade produto' (...) a que chega é de fato justamente uma resposta ao indivíduo pós-moderno, desatrelado e soberano de Stirner" (Souza, 1993, p.187).

Entendendo que as críticas dos debates jovens hegelianos dirigidas ao idealismo foram tentativas de desenvolver uma crítica cabal à modernidade, podemos situar

8 Para Nicholas Lobkowicz, por exemplo, esse “estilo" é mesmo proposital (Souza, 1993, p.186). 
Stirner também desse modo, no próprio debate jovem hegeliano. O que nos leva à terceira linha de leitura do autor.

\section{Stirner crítico da Modernidade}

Na apresentação de A Questão da Individualidade: a crítica do humano e do social na polêmica Stirner-Marx, José Crisóstomo de Souza adjetiva Stirner como um “niilista pós-moderno" (Souza, 1993, p.7). George Woodcock, salvaguardando um pouco sua interpretação anarquista, reconhece que Stirner também "aproxima-se do niilismo e do existencialismo" (Woodcock, 2010, p.103). Para Franco Volpi, Stirner representa “[a] primeira teorização autêntica de uma posição filosófica que pode ser definida como niilismo, ainda que omitindo o uso desse conceito" (Volpi, 1999, p.33). Nesse quadro contemporâneo onde é, assim, colocado Stirner, podemos orientar uma terceira linha de estudo do filósofo: o de um modernista.

O filósofo alemão contemporâneo Jürgen Habermas, no terceiro capítulo do seu O Discurso Filosófico da Modernidade (1985), intitulado "Três perspectivas: hegelianos de direita, hegelianos de esquerda e Nietzsche", define do seguinte modo os direcionamentos pós-hegelianos na modernidade:

A crítica dos hegelianos de esquerda, voltada para a prática e atenta à revolução, quer mobilizar o potencial da razão historicamente acumulado, que aguarda ser liberado, contra a mutilação da razão, contra a racionalização unilateral do mundo burguês. Os hegelianos de direita seguem Hegel na convicção de que a substância do Estado e da religião compensará a inquietação da sociedade burguesa (...). Nietzsche quer, enfim, desmascarar a dramaturgia da peça inteira em que se apresentam tanto a esperança revolucionária quanto a reação (Habermas, 2000, p.81).

Em suas observações sobre a modernidade, e ainda sobre os pós-hegelianos de maneira geral, Habermas não se refere a Max Stirner. Mas podemos perceber nesse trecho que o filósofo d'o Único seria muito mais próximo da linha que Habermas atribui a Nietzsche, o niilista mais popular da história da filosofia contemporânea. É frequente entre comentadores de Stirner, ou do pós-hegelianismo, associá-lo a Friedrich Nietzsche (Cf. Löwith, 2014; e Souza, 1993). J. Crisóstomo de Souza identifica essa associação entre os dois filósofos como a mais expressiva para Stirner (Souza, 1993, p.178). Karl Löwith destaca ainda que Moses Heß usa "além-do-homem" (Übermensch), para se referir ao sujeito baueriano, e "inumano" (Unmensch), ao stirneriano; e acrescenta:

A tese de Bauer, segundo a qual o homem, na religião cristã, venera a "inumanidade" como sua essência, corresponde à tese de Stirner, que, enquanto Cristo seja o alémdo-homem, o homem não é ainda nenhum eu. (...) A esta conexão entre o homemDeus. O Cristo, ou seja, o homem entendido à maneira cristã, e aquele que é para si mesmo um eu singular, que em relação àquele primeiro é um "não-homem", 
corresponde em Nietzsche à não menos coerente conexão entre a morte de Deus e à superação do homem com o além-do-homem, que vence a Deus e ao nada (Löwith, 2014, p.233). ${ }^{9}$

Pelo mesmo aspecto anti-idealista que levou Nietzsche a comumente ser colocado no extremo oposto de Platão é que, na introdução de Sade, Stirner, Nietzsche: la comunicazione impossibile, Alberto Signorini define a filosofia de Stirner como "anti-platônica por excelência, rejeitando o mundo da essência ideal, o universo das ideias" (Signorini, 1980, p.7). Nesta mesma medida de crítico do pensamento idealista, Stirner é também lido como um filósofo relacionado ao existencialismo, isto associado à sua “filosofia egoísta” (o desenvolvimento do único), presente na segunda parte de $O$ Único e sua Propriedade, "onde é colocado em foco a realidade existencial do eu” (Penzo, 1996, p.492), quando ele desenvolve sua explicação sobre a singularidade e o egoísmo que "claramente antecipam o existencialismo" (Gordon, 1978, p.61). Para Giorgio Penzo, "a crítica de Stirner visa, no fundo, superar a razão iluminista, que afirmava ser o fundamento último da verdade” (Penzo, 1996, p.490). Segundo esse comentador, o idealismo que Stirner critica ainda permanece ligado "a uma concepção de verdade que permanece, ao fundo, unida ao plano do iluminismo" (idem, p.488).

Dessa maneira, como crítico da modernidade, Stirner é lido também como um proto-existencialista, uma espécie de pós-moderno, no sentido de anti-idealista, anti-platônico, anti-metafísico. Ele inauguraria com seu único - egoísta, criador e proprietário - a fase "adulta" do pensamento, de acordo com o que ele mesmo havia sugerido, quando compara a criança ao realista (o que idealiza o real), o jovem ao idealista (o que quer realizar o ideal) e o adulto ao egoísta (Stirner, 2009, p.22): uma fase caracterizada pelo abandono de conceitos hipostasiados e absolutos.

Quando Herbert Marcuse afirma que "no sistema de Hegel todas as categorias acabam por se aplicar à ordem existente, enquanto que no sistema de Marx elas se referem à negação desta ordem" (Marcuse, 2011, p.225), podemos estender, de modo geral, ao próprio movimento jovem hegeliano essa virada atribuída a Marx. Ao escrever $O$ Único, Stirner não pensa num tratado filosófico, mas debate diretamente com seus contemporâneos, que ele considera a expressão mais recente da modernidade - os modernos, Die Neuen, os idealistas (cf. Stirner, 2009, p.22 e p.128). A isso podemos somar as observações de J. Crisóstomo de Souza:

[N]a Modernidade, o objeto apenas se transforma, sem perder em nada sua potência. (...) A filosofia moderna teria superado o dado e o estabelecido, contudo não instaurou em seu lugar o eu absolutamente livre, antevisto pelo jovem Schelling. Em vez disso, a dúvida cartesiana resultou ser o início do império do pensamento, que o idealismo

9 “Desde o momento em que Nietzsche concebeu a plena importância do grande 'acontecimento' de que Deus está morto para a humanidade do homem, ele, ao mesmo tempo, reconheceu que a morte de Deus é, para o homem, que se quer a si mesmo, a liberdade para a morte” (Löwith, 2014, p.233). 
alemão hegeliano levou ao apogeu no "conceito". Por isso a filosofia moderna, apesar de tudo, ainda se volta contra o que é "puramente subjetivo" (...). E não quer que as coisas sensíveis sejam vistas prosaicamente, na forma em que a nada nos obrigam (Souza, 1992, pp.98-99).

Podemos, ainda, por fim, acrescentar a conclusão desse mesmo comentador de que "a obra stirneriana está presente na cultura do nosso tempo, não explicitamente, mas como 'metacultura'” (1993, p.182).

Entender Stirner como um crítico da modernidade, no sentido de crítico de determinado vocabulário filosófico, é o que nos permite lê-lo como um dissolvedor do idealismo recente em sua época. Essa crítica, pretendida por tantos, encontra em Stirner sua forma mais radical e completa justamente porque ele não apenas atinge o conteúdo das ideias, mas antes o seu fundamento. Para o pensamento stirneriano as ideias são fantasmas que querem nos possuir, tornar-se nossa causa e nosso horizonte, nossos proprietários, quando são meras criações nossas e, portanto, nossas propriedades, sejam essas ideias Deus, Espírito, Estado, Liberdade ou Sociedade. Mas essa reflexão ele a faz insurgindo-se de dentro do romantismo e do hegelianismo, de seu vocabulário; de seu tempo e contexto, para o seu tempo e contexto. Um filósofo modernista.

\section{Referências}

Arantes, P. E. (1996). Ressentimento da Dialética: Dialética e Experiência intelectual em Hegel. Rio de janeiro, RJ: Paz e Terra.

Armand, E., Barrué, J. \& Freitang, G. (2003). Max Stirner e o Anarquismo Individualista. Tradução e seleção de Plínio Augusto Coêlho. São Paulo, SP: Imaginário.

Bookchin, M. (2010). Anarquismo, Crítica e Autocrítica. Tradução de Felipe Corrêa e Alexandre B. de Souza. São Paulo, SP: Hedra.

Bauer, B. (1989). The Trumpet of the Last Judgment Against Hegel the Atheist and Anti-Christ: An Ultimatum. Translated by Lawrence Stepelevich. Lewiston/ Lampeter/Queenston: The Edwin Mellen Press.

Díaz, C. (2002). Max Stirner: Uma filosofia radical do Eu. Tradução de Piero Angarano e Jorge E. Silva. São Paulo, SP: Imaginário.

Engels, F. (s/d). "Ludwig Feuerbach e o Fim da Filosofia Clássica Alemã”. In: Marx/ Engels - Obras Escolhidas (Volume 3). São Paulo, SP: Editora Alfa-Omega, pp.169207.

Feuerbach, L. (1978). The Essence of Christianity in Relation to The Ego and Its Own. Translated by Frederick M. Gordon. The Philosophical Forum, 8 (2-4), pp.81-91. 
. (2009). Preleções sobre a Essência da Religião. Tradução de José da Silva Brandão. Petrópolis, RJ: Vozes.

Gordon, F. M. (1978). The debate between Feuerbach and Stirner: an introduction. The Philosophical Forum, 8 (2-4), pp.52-65.

Habermas, J. (2000). O Discurso filosófico da modernidade. Tradução de Luiz Sérgio Repa e Rodnei Nascimento. São Paulo, SP: Martins Fontes.

Löwith, K. (2014). De Hegel a Nietzsche. Tradução de Flamarion Caldeira Ramos e Luiz Fernando Barrére Martin. São Paulo, SP: Editora da UNESP.

Marcuse, H. (2011). Razão e Revolução: Hegel e o advento da teoria social. Tradução de Marília Barroso. São Paulo, SP: Paz e Terra.

Marx, K. (2005). "Para a Crítica da Economia Política”. In: Coleção Os Pensadores Marx. Tradução de Edgard Malagodi. São Paulo, SP: Nova Cultural, pp.23-54.

Marx, K. \& Engels, F. (1956). „Briefwechsel von Marx \& Engels“. In: Marx \& Engels Werke (Band 37). Berlim, Dietz Verlag.

. (2007). A Ideologia Alemã. Tradução de Rubens Enderle, Nélio Schneider e Luciano Cavini Martorano. São Paulo, SP: Boitempo.

Penzo, G. (1996). "Interpretazione Esistenziale di Stirner e La Polemica Stirneriana con Marx". In: Instituto Suor Orsola Benincasa, Max Stirner e L'Individualismo Moderno. Napoli: Cuen.

Signorini, A. (1980). Sade, Stirner, Nietzsche: la comunicazione impossibile. Pubblicazioni della Facoltà di Giurisprudenza della Università di Camerino: Jovene Editore.

Souza, J. C. de (1992). Ascensão e Queda do Sujeito no Movimento Jovem Hegeliano. Salvador, BA: Centro Editorial e Didático da UFBA.

- (1993). A Questão da Individualidade: a crítica do humano e do social na polêmica Stirner-Marx. Campinas, SP: Editora da UNICAMP.

Stepelevich, L. (1999). The Young Hegelians: An Anthology. New York: Humanity Books.

. (2005). "Hegel and Stirner". In: Moggach, D. (Org.). The Left Hegelians: New Philosophical and Political Perspectives. Cambridge: Cambridge University Press.

Stirner, M. (1978). Stirner's Critics. Translated by Frederick M. Gordon. The Philosophical Forum, 8 (2-4), pp.66-80.

. (2009). O Único e sua Propriedade. Tradução de João Barrento. São Paulo, SP: Martins Fontes.

. (2011). Max Stirner's Kleineres Schriften: Und Seine Entgegnungen Auf Die Kritik Seines Werkes. "Der Einzige Und Sein Eigentum" Aus Den Jahren 1842-1848. Org. John Henry Mackay. La Vergne, TN: Nabu Press.

Volpi, F. (1999). O Niilismo. Tradução de Aldo Vannucchi. São Paulo, SP: Edições Loyola. 
Rodrigo Ornelas

Wartofsky, M. W. \& SaSS, H-M (1978). Editor's Note. The Philosophical Forum, 8 (24), pp.1-5.

Woodcock, G. (2010). História das Ideias e Movimentos Anarquistas - Vol. 1: a Ideia. Tradução de Júlia Tettamanzy et al. Porto Alegre, RS: L\&PM. 